\title{
Photosynthesis of Palladium Nanoparticles at the Water/Oil Interface
}

\author{
Kang Yeol Lee, ${ }^{\neq \neq}$Hee-Seop Byeon, Jae-Kyung Yang, Gang-Won Cheong, ${ }^{\ddagger . \neq}$ and Sang Woo Han ${ }^{\dagger+. . *}$ \\ ${ }^{\dagger}$ Department of Chemistry and Research Institute of Natural Science, Gyeongsang National Chiversit, Jinju 660-701. Korea \\ ${ }^{*}$ E-mail: swhaniàgniack ${ }^{r}$ \\ ${ }^{\ddagger}$ Emirommental Biotechnologv National Core Research Center, Gveongsang National Cniversin, Jimju 660-701. Korea \\ ¿Faculty of Forest Science and Institute of Agriculture \& Life Sciences. Gveongsang National Liviversin, Jinju 660-701. Korea \\ "Division of Applied Life Sciences, Greongsang National Lniversin, Jinju 660-701. Korea \\ Received March 14, 2007
}

Key Words : Photosynthesis. Water/oil interface, Pd nanoparticles, Interfacial films

Metal nanostructured materials have been the focus of much scientific research for decades because of their unusual electronic optical magnetic thermal catalytic and other properties that are distinctly different from their bulk counterparts. and therefore considerable attention from both fundamental and applied research has been paid to the synthesis and characterization of these materials. ${ }^{1}$ Particular interest has been focused on the noble metal nanoparticles due to the fact that they show interesting size- and shapedependent physical and chemical properties ${ }^{\mathrm{l}}$ and they are teclunologically important in many fields such as cataly sis. ${ }^{\hat{3}, \hat{3}}$ optics, ${ }^{4}$ and surface enlhanced Ranian spectroscopy ${ }^{56}$ Among the known metal nanoparticles. palladium is widely studied because of its characteristic optical spectroscopic magnetic and catalytic properties. The development of the preparation of uniform palladium nanoparticles becomes a very important issue in their application to heterogeneous catalysis and to the hydrogen storage materials.

Several synthetic approaches and different palladium precursors have been applied to generate palladium nanoparticles having different shapes and sizes: chemical reduction of $\mathrm{PdCl}_{2}$ by $\mathrm{NaBH}_{4}{ }^{8}$ and by arc-discharge. ${ }^{9}$ reduction of $\mathrm{Pd}(\mathrm{OAc})_{2}$ in supercritical carbon dioxide, ${ }^{11}$ thermally induced reduction of $\mathrm{Pd}(\mathrm{Fod})_{\mathrm{s}}{ }^{11}$ and sonochemical reduction of $\mathrm{PdCl}_{2}{ }^{1}{ }^{13}$ To prevent the formation of undesired agglomerates of palladium nanoparticles. the processes have been performed in the presence of various surfactant molecules. ${ }^{13}$ The size and shape of palladium nanoparticles have been discussed as a function of metal precursor concentration and of the effect of the surfactant molecules. However. the aqueous-phase synthesis of uniform nanoparticles by envirommentally friendly process is still challenging.

In this work, we present a study of the photosynthesis of palladium nanoparticles at the water/oil interface without any additional templates and reducing agents. We found that palladium nanoparticles can be easily formed by irradiating biphasic mixture consists of diethyl ether and aqueous palladium salt solution with a conventional fluorescent light. The physicochemical characteristics of the prepared nanoparticles were examined by various analytical tools such as scanning electron microscopy (SEM), transmission electron microscopy (TEM). energy dispersive X-ray spectroscopy (EDX). and X-ray photoelectron spectroscopy (XPS).

\section{Experimental Section}

$\mathrm{K}_{2} \mathrm{PdCl}_{4}$ was purchased from Aldrich. Other chemicals, unless specified. were reagent grade, and triply distilled water (resistivity greater than $18.0 \mathrm{M} \Omega \mathrm{cm}$ ) was used when preparing aqueous solutions.

Palladium nanoparticles were fabricated as follows. $5 \mathrm{~mL}$ of freshly prepared $\mathrm{K}_{2} \mathrm{PdCl}_{4}$ aqueous solution $(5 \mathrm{mM})$ was taken in a vial along with $5 \mathrm{~mL}$ of diethyl ether resulting in a biphasic mixture with the colorless organic part on top and yellow-colored aqueous solution below. The system is then irradiated with a conventional 45 -W fluorescent light for 12 hr. A thin film is formed slowly at the liquid/liquid interface. The interfacial films could be easily transferred to solid substrates. In fact. the biphasic mixture was poured into a Petri dish and the diethyl ether phase evaporated to leave a uniform film on the surface of water. This film was lifted onto mica substrates and carbon-coated TEM grids for further analy'sis.

The scanning electron micrographs and EDX data of the samples were taken with field emission scanning electron microscope (FESEM. Phillips Model XL30 S FEG). The TEM images were acquired by using a JEOL JEM-2010 transmission electron microscope operating at $200 \mathrm{kV}$. XPS measurements were carried out using a VG Scientific ESCALAB 250 spectrometer. using Al $K \alpha$ X-ray (1486.6 $\mathrm{eV}$ ) as the light source. The base pressure of the chamber was $\sim 1 \times 10^{-11}$ Torr and the electron take-off angle was $90^{\circ}$.

\section{Results and Discussion}

The freshly prepared aqueous solution of $\mathrm{K}_{2} \mathrm{PdCl}_{4}(5 \mathrm{mM})$ was taken in a vial along with diethyl ether resulting in a biphasic mixture with the colorless organic part on top and yellow colored hydrosol below (inset of Figure 1a. left). After irradiation of this mixture with a conventional $45-\mathrm{W}$ fluorescent light for $12 \mathrm{hr}$. a thin film with black color is formed at the water/oil interface (inset of Figure la. right). The interfacial film could be transferred to mica substrates and carbon-coated TEM grids and then studied by SEM. EDX. TEM. and XPS

Figure la shows a typical SEM image of the transferred film on mica. From the SEM image. it is clearly seen that the 
(a)

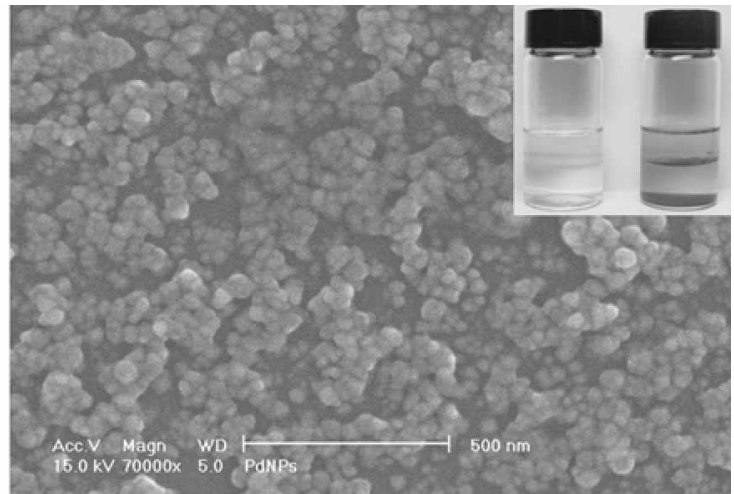

(b)

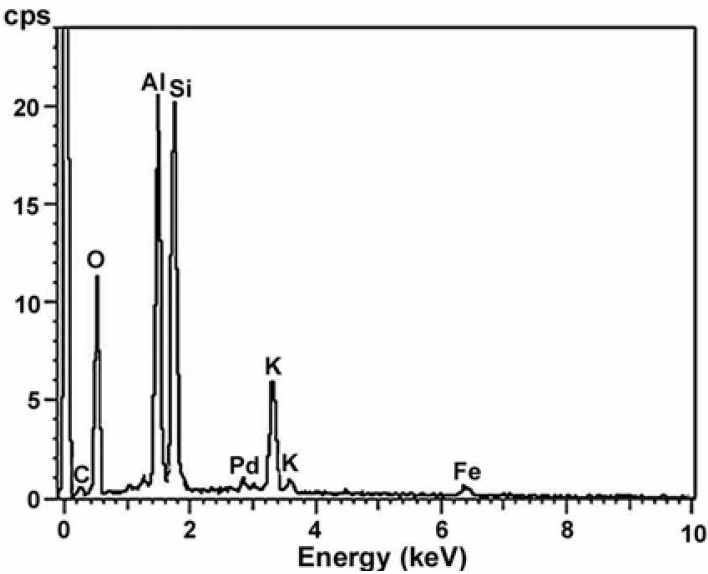

Figure 1. (a) SEM image of the interfacial filln transferred to mica substrate. The inset shows vials before (vial on the left) and after (vial on the right) irradiation with a conventional $45-\mathrm{W}$ fluorescent light for $12 \mathrm{hr}$. (b) EDX spectrum of the film shown in (a). All peaks except $P d$ are due to the mica substrate.

as-prepared product consists of nano-sized particles. The presence of $\mathrm{Pd}$ in the sample was confirmed by EDX analysis during the SEM observation (Figure lb). The palladium nanoparticle shape and size in the interfacial film and their distribution have been investigated using TEM. A typical TEM image of the transferred film on carbon-coated TEM grid is presented in Figure 2a. The higher magnification TEM image of the film is also presented in the inset of Figure 2a. As shown in TEM images. the photochemical reduction of $\mathrm{Pd}(\mathrm{II})$ ions leads to the formation of nanoparticles which are clearly separated and have. in general. a rounded shape. The size distribution of the prepared particles is relatively wide. with average diameter of about $19.2 \pm 7.4 \mathrm{~nm}$. The electron diffraction pattem obtained by focusing the electron beam on palladium nanoparticles lying flat on the TEM grid is shown in Figure 2b. The observed diffraction rings can be assigned to the (111). (200). (220). and (311) diffractions of Pd metal with face-centered cubic (fcc) structure. This indicates the existence of a fcc structure of palladium in the nanoparticles.

We have used the aqueous/organic biphasic system as a reaction medium for the fabrication of palladium nanoparticles because nanostnuctured materials can be readily assembled at the aqueous/organic interface ${ }^{1+, 15}$ At the interface, self-assembly of nanoparticles is dictated by a minimi-

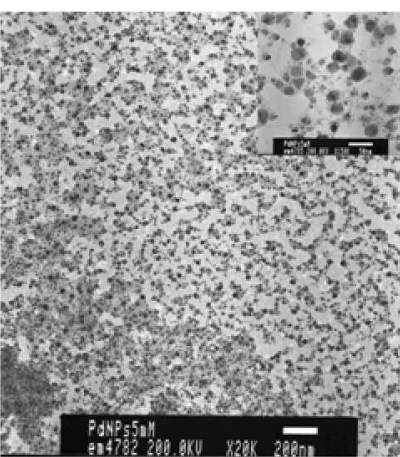

(a)

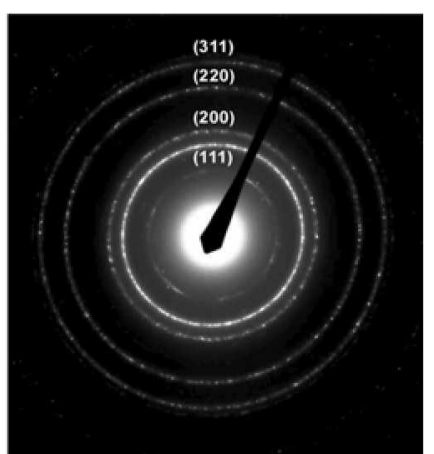

(b)
Figure 2. (a) TEM image of the palladium nanoparticles. The enlarged image is shown in the inset. (b) Electron diffraction pattern of the obtained palladium nanoparticles.

zation of the interfacial energy. From this interfacial entrapment process. palladium nanoparticles can be easily collected without further purification step such as centrifugation Indeed. the interfacial films can be collected by transferring them to solid substrates

In the previous studies on the assembly of nanoparticles at the liquid/liquid interface, ${ }^{1+, 15}$ it was observed that the interfacial film was uniformly composed of extremely large domains of the nanoparticle monolayers without any apparent disruption in the close-packed assembly of the nanoparticles. In the domain, the nanoparticles are in-plane packed with very regular pattern and the particles in the 2-D assembly are to a large extent well separated from one another. Other earlier studies have demonstrated the very regular, hexagonal arrangement of silica-coated gold nanoparticles ${ }^{16}$ as well as CdSe quantum dots. ${ }^{17}$ In the present study. however. palladium nanoparticles film does not show well-ordered structure. It could be due to the fact that the palladium nanoparticles of this study are not monodisperse (ca. $38 \%$ standard deviation) and it is known that this level of polydispersity does not lead to good two-dimensional ordering.

To gain more insight into the prepared nanoparticles. we have performed XPS measurements. XPS tumed out to be a powerful tool for the investigation of metal nanoparticles. ${ }^{18}$ High-resolution Pd 3d X-ray photoelectron spectrum of the palladium nanoparticles is shown in Figure 3. As shown in the figure. Pd 3d XPS spectrum obtained from the palladium nanoparticles films was characterized by peaks with binding energies of $335.10 \mathrm{eV}$ for $3 \mathrm{~d}_{3}$ and $340.35 \mathrm{eV}$ for $3 \mathrm{~d}_{3: 2}$. both distinctive for Pd metal. ${ }^{19}$ The line shape of the highresolution $\mathrm{Pd} 3 \mathrm{~d}_{2: 2}$ peak indicates that there are three types of valent states. As shown in Figure 3, the main component at binding energy of $335.10 \mathrm{eV}$ corresponds to a zero-valent state of Pd. while the minor components at 336.30 and $337.90 \mathrm{eV}$ are assigned to a nonzero-valent state. ${ }^{19}$ The presence of nonzero-valent state of $\mathrm{Pd}$ indicates the formation of $\mathrm{PdO}$ or $\mathrm{PdO}_{2}$ on the surface of nanoparticles. In fact, the fomation of PdO layer on the surface of the palladium nanoparticles by the oxidation of $\mathrm{Pd}$ by air has also been 

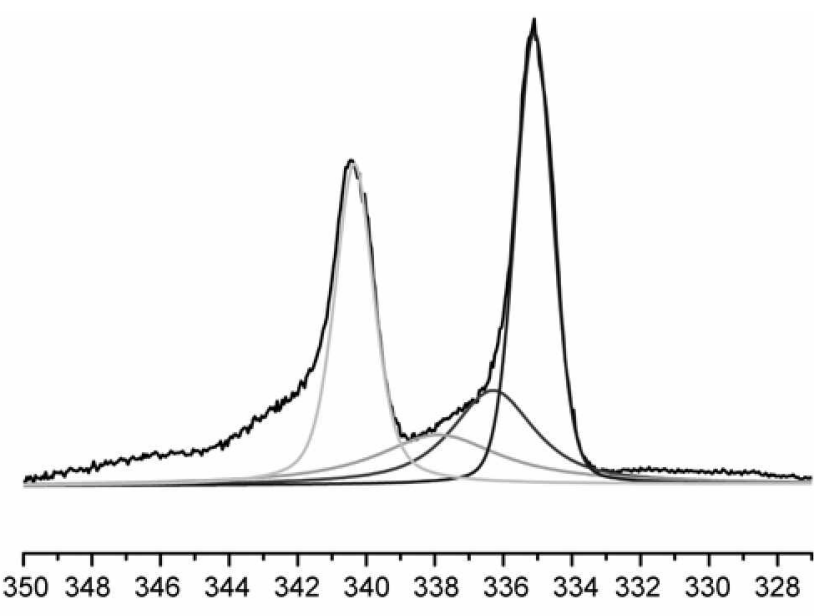

Binding Energy (eV)

Figure 3. High-resolution Pd 3d XPS teatures obtained from palladium nanoparticles.

reported in the previous literature.

In this work, we have used the conventional fluorescent light illunination to the biphasic nuixture consists of diethyl ether and aqueous metal salt solution as a new approach to the synthesis of metal nanoparticles. All the previous photochemical or photocatalytic methods for metal nanoparticle preparation are based on the use of UV light ${ }^{11.22}$ Direct photochenical excitation of metal ion precursors under 254 Int irradiation can lead to the generation of metal nanoparticles in aqueous solution with surfactant as a stabilizer. For example, the photolysis of $\mathrm{AuCl}_{4}^{-}$. $\mathrm{PtCl}_{6}{ }^{--}$. or $\mathrm{Ag}^{+}$by $254 \mathrm{~nm}$ induced the fornation of metal nanoparticles in the presence of surfactants that prevent nanoparticles from agglomerating ${ }^{21.22}$ Thin palladium film on a Si substrate produced by vacuum ultraviolet (VUV) induced decomposition of palladium acetate has also been reported. ${ }^{t 3}$ The formation of palladium nanoparticles by visible light irradjation may be ascribed to the fact that aqueous $\mathrm{PdCl}_{4}{ }^{2-}$ solution shows a prominent broad absorption feature in the visible range (centered at $420 \mathrm{~nm}$ ). The emission spectrum of the fluorescent tube used as the excitation source exhibits bands at $405 \mathrm{~mm}$ and $435 \mathrm{~nm}$. These emission bands can thus induce photochemical excitation of metal ion precursor and can lead to the formation of nanoparticles.

\section{Conclusions}

We have developed a facile and effective solution-phase method for fabrication of palladiun nanoparticles by visible light irradiation of the diethyl ether/aqueous solution of palladium salt biphasic mixture. Our synthetic approach does not require any additional templates and reduction agents. and thus offers not only an attractive possibility for the manufacture of thin film microcircuits and devices, but also could offer a very efficient and economic technique for the preparation of nanoparticles. The resulting palladium nanoparticles would be expected to be useful for applications ranging from high-efficiency computing. fuel cell, hydrogen storage. light harvesting in photovoltaic cells, to supersensitive sensors. Currently. we are attempting to synthesize other metal nanoparticles by using various metal precursors.

Acknowledgment. This work was supported by the Korea Research Foundation Grant funded by the Korean Govennment (MOEHRD) (KRF-2006-311-C00355). by a grant from the MOST/KOSEF to the Environmental Biotechnology National Core Research Center (grant \#: R15-2003-01201001-0), and by Tecluology Development Program of the Ministry of Agriculture and Forestry. Republic of Korea.

\section{References}

1. (a) Nanoporticles and Nanostructured Films: Fendler. T. H.. Ed: VCH: Weinheim. Gemnany. 1998. (b) Klabunde. K. T. Nanoscale Materials in Chemistry: VCH: Weinheim. Germany. 2001. (c) Schmid. G. Chem Rev 1992. 92, 1709. (d) Roucoux. A.: Schulz. J.: Patin, H. Chem. Rev: 2002. 102. 3757.

2. Narayana, R.: El-Sayed. M. A. Kono Lett. 2004. 4. 1343.

3. Lewis. L. N. Chent Rev 2001. 93. 2693.

4. Kamat. P. V. J. Phys. Chen. B 2002. 106. 7729.

5. Tian. Z. Q.: Ren1. B.: Wu. D. Y. J. Phys. Chent. B 2002. 106.9463.

6. Han. S. W: Lee, K. Y. Bull Korean Chem. Soc. 2005. 26. 1427.

7. Pintar. A.: Batısta. J.: Levec, J. Catal Today 2001. 66, 503.

8. Jana, N. R.: Wang, Z. L.; Pal. T. Langmir 2000. 16. 2457.

9. Bera. D:: Kuiry. S. C.: McCutchen. M.: Kruize. A.: Heinrich. H.: Meyyappan. M.: Seal. S. Chem. Phws. Lett. 2004. 386. 364.

10. Kameo. A.: Yoshimura. T.: Esumi. K. Colloid Sinf A 2003. 215. 181 .

11. Ho. P. F: Chi. K. M. Nanotechologv 2004. 15. 1059.

12. Okitsu, K.: Bandow. H.: Maeda. Y. Chem. Hater 1996. 8. 315.

13. (a) Jiang. G.: Wang. L:: Chen. T.: Yu. H.: Wantg. T. Namotechologe 2004. 15. 1716. (b) Choo. H. P.: Liew. K. Y.: Liu. H. J. Mater. Chent 2002. 12. 934. (c) Ramirez. E.: Tansat. S.: Philippot. K.: Lecante, P.: Gomez. M:; Masdeul-bulto, A. M: Chaudret, B. $d$. Organonet Chem 2004, 689, 4601 .

14. Lee. K. Y.: Bae. Y; Kim, M; Cheong. G.W; Kim, J; Lee, S. S; Hant. S. W. Thin Solid Finnts 2006. 515.2049.

15. Lee. K. Y.: Hant. S. W. Bull Korean Chem. Soc. 2005. 26.1306.

16. Liz-Marzan. L. M.: Giersig. M.: Mul vaney. P. Langmtir 1996. 12. 4329.

17. Letf, D. V: Brandt. L.: Heath, J. R. Langmir 1996. $12,4723$.

18. Lee. K. Y; Kim. M.: Hahn. J ; Suh, J. S.; Lee, I.; Kim. K.: Han, S. W. Langnuir 2006. 22.1817.

19. Moulder. J. F.: Stickle. W. F.: Sobol. P. E.: Bomben. K. D. Handbook of A-Ray Photcelectron Spectroscopy. Perkin-Elmer: Eden Prairie. MN. 1992.

20. Xiong. Y.: Chen, J.: Wiley, B.: Xia, Y.: Ym, Y: Lı. Z.-Y. Nano Lett. 2005, $5,1237$.

21. (a) Esumi. K.: Matsuhisa. K.: Torigoe. K. Langmir 1995. 1 . 3285. (b) Pal. A.: Ghosh. S. K.: Esumi. K.: Pal. T. Langmitir 2004. 20.575. (c) Kim. F.: Song. J. H.: Yan1g. P. J. Am. Chent Soc. 2002. 124. 14316 .

22. Lee. J.: Ryu, J.; Choi. W. Chem Lett. 2007. 36. 176.

23. Fang. Q; He, G. Cai. W. P. Zhang. J.Y.; Bovd, 1. W. Appl Swf. Sci. 2004.226 .7$. 